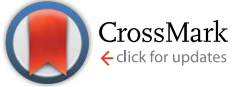

Cite this: Chem. Sci., 2017, 8, 366

\title{
Decoupling stability and release in disulfide bonds with antibody-small molecule conjugates $\uparrow$
}

\author{
Thomas H. Pillow, ${ }^{\star}$ Jack D. Sadowsky, Donglu Zhang, Shang-Fan Yu, Geoffrey Del \\ Rosario, Keyang Xu, Jintang He, Sunil Bhakta, Rachana Ohri, Katherine R. Kozak, \\ Edward Ha, Jagath R. Junutulaß and John A. Flygare
}

\begin{abstract}
Disulfide bonds provide a bioactivatable connection with applications in imaging and therapy. The circulation stability and intracellular release of disulfides are problematically coupled in that increasing stability causes a corresponding decrease in cleavage and payload release. However, an antibody offers the potential for a reversible stabilization. We examined this by attaching a small molecule directly to engineered cysteines in an antibody. At certain sites this unhindered disulfide was stable in circulation yet cellular internalization and antibody catabolism generated a disulfide catabolite that was rapidly reduced. We demonstrated that this stable connection and facile release is applicable to a variety of payloads. The ability to reversibly stabilize a labile functional group with an antibody may offer a way to improve targeted probes and therapeutics.
\end{abstract}

Received 26th April 2016

Accepted 10th August 2016

DOI: $10.1039 /$ c6sc01831a

www.rsc.org/chemicalscience

ability to release the payload. In many applications, including antibody-drug conjugates (ADCs), high stability of the disulfide in circulation and low stability of the disulfide within the target cell are desired. Disulfides are reduced in the cytosol of cells where the concentration of reduced glutathione (GSH) is 1-10 $\mathrm{mM}$ whereas cysteine (Cys) is the most abundant reactive thiol in plasma with concentrations between $8-11 \mu \mathrm{M} .{ }^{15}$ While this 1000 fold difference in reactive thiol concentration is the basis for the use of disulfides in drug delivery, the lack of exquisite selectivity for reduction by GSH versus Cys leads to a coupling of stability and release. Unhindered disulfides provide the most facile reduction in the cytosol but the lowest stability in circulation. Increasing the stability of the disulfide bond with adjacent alkyl groups increases circulation half-life, have introduced the disulfide via a heterobifunctional crosslinker between the drug or probe and lysine (Lys) residues on the protein. Given the number of reactive Lys residues in most proteins, the result is a highly heterogeneous conjugate with a varying number of drugs at a large number of sites (Fig. 1a). ${ }^{12}$ This heterogeneity presents challenges for characterization and analysis, but more importantly can reduce activity and increase toxicity. ${ }^{\mathbf{1 3 , 1 4}}$

The second even bigger challenge when attaching small molecules to proteins through heterobifunctional disulfide linkers is that the stability of the conjugate is coupled to the

Research \& Early Development, Genentech, Inc., 1 DNA Way, South San Francisco, CA 94080, USA. E-mail: thomashp@gene.com

$\dagger$ Electronic supplementary information (ESI) available. See DOI: 10.1039/c6sc01831a

\$ Present address: Solstice Biologics, San Diego, CA 92121, USA.

$\S$ Present address: Cellerant Therapeutics, San Carlos, CA 94070, USA.

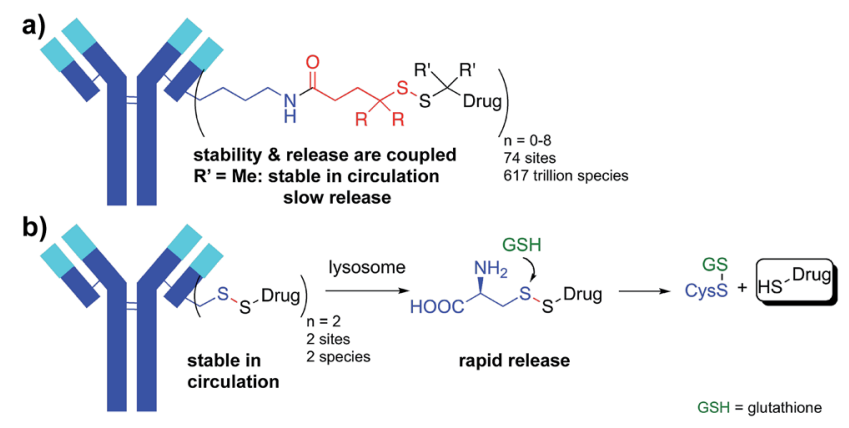

Fig. 1 Antibody-small molecule drug conjugates with disulfide linkers. (a) Heterogeneous Lys conjugates formed through heterobifunctional cross-linkers have a stability and release that are coupled. (b) Decoupling stability and release: site-specific Cys conjugates effect drug release through lysosomal proteolysis and subsequent disulfide reduction. 
but hinders release of the free drug in the target cell. Achieving the desired stability and release is therefore a balancing act. The disulfide conjugates that have advanced into human clinic trials have typically had an intermediate level of alkyl substitution around the disulfide (1-2 methyl groups on either side of the disulfide). ${ }^{16,17}$ For example, in maytansine disulfide conjugates (Fig. 1a, $\mathrm{R}=\mathrm{H}, \mathrm{R}^{\prime}=\mathrm{Me}$; SPDB-DM4), the drug becomes deconjugated from the antibody in circulation with a half-life of $\sim 9$ days ${ }^{18}$ while a major catabolite in tumors for the first 4 days is the unreduced disulfide. ${ }^{19}$ While poorly reducible and even non-cleavable linkers for some payloads can afford efficacious ADCs, they are often limited to targets with high and homogeneous antigen expression. ${ }^{20}$ The approach of balancing stability and release has led to a sacrifice in one or both potentially critical attributes.

Described herein is an approach to simultaneously achieve high stability in circulation and fast payload release in a target cell for disulfide-linked antibody conjugates. To achieve high stability in circulation we connected a small molecule drug directly via a disulfide to the two free thiols of a Cys-engineered antibody at a variety of mutant sites. Target cell internalization and degradation of the antibody by the lysosome then permitted facile cleavage of the disulfide bond by cytosolic reductants (e.g. GSH) and release of the drug (Fig. 1b). Our approach has several advantages. Rather than extending the disulfide away from the protein as is done with most disulfide conjugates through the use of heterobifunctional linkers, the direct approach brings the disulfide bond as close as possible to the antibody. By connecting the disulfide directly to the antibody we can take advantage of a steric protection resulting from reduced solvent accessibility at some sites in a three-dimensional folded protein. While others have investigated attaching drugs through disulfide bonds at different sites in smaller proteins, none of these approaches resulted in in vivo stability sufficient for antibody-mediated delivery and stability remained problematically coupled to release. ${ }^{21-23}$ This approach also reduces the heterogeneity in the resulting conjugate since drugs are specifically attached to the engineered Cys residues. Since only a single bond links the drug to the antibody, cleavage releases unmodified drug and antibody fragment without the need for a linker. ${ }^{24}$

\section{Results and discussion}

To test the design concept we utilized thiol-containing derivatives of the natural product maytansine..$^{25}$ Derivatives DM1 (1) and DM3 (2), differing primarily in the addition of a methyl group next to the disulfide, were first treated with activating agent 3 followed by reaction with the engineered Cys of an antiCD22 antibody (Scheme 1). We selected antibody site LC-V205C as a starting point as it offered the greatest stability for maleimide-linked conjugates in previous studies. ${ }^{26}$

We evaluated the V205C-DM1 conjugate for in vivo stability (Fig. 2a). Interestingly, while we previously demonstrated that conjugates linked to V205C using maleimide chemistry were highly stable with minimal drug loss in vivo up to 21 days, we

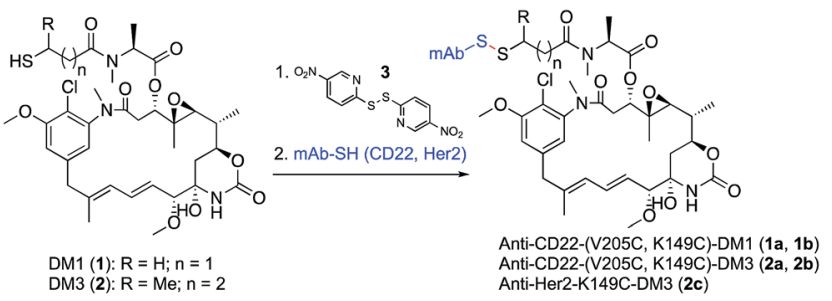

Scheme 1 Synthesis of site-specific antibody-maytansine conjugates through disulfide activation. Drug-to-antibody ratios (DARs) were uniform, ranging between 1.8 and 2.0.

found that a DM1 conjugate (1a) linked at the same site through a disulfide bond was quite unstable.

Within one day, about half of the unhindered drug (DM1, 1) was lost in circulation. Mass spectrometry analysis indicated that a disulfide displacement had occurred, resulting in loss of drug and addition of Cys and GSH to the antibody (Fig. S1†).

Based on these results we sought antibody sites that would generate more stable disulfide conjugates. A screen of several mutation sites led ultimately to the identification of LC-K149C as a stable conjugation site for disulfides (manuscript in preparation). When we attached DM1 (1) through a disulfide to K149C (1b), only about $10 \%$ of the drug was lost after one day, and even after seven days, more than $50 \%$ of the drug remained attached (versus $56 \%$ and $100 \%$ loss after 1 and 7 days, respectively, for LC-V205C, 1a). The stability of unsubstituted disulfide conjugate $\mathbf{1 b}$ is comparable to that of the Lys-linked disulfide conjugate with two neighboring methyl groups (SPDB-DM4). ${ }^{18}$ Furthermore, addition of just one methyl group next to the disulfide (DM3, 2) resulted in conjugates possessing increased stability at both sites on the antibody with the LC-K149C conjugate (2b) losing only $10 \%$ of the drug after seven days.

We next evaluated anti-tumor effects of anti-CD22 disulfide conjugates in a human lymphoma tumor xenograft in mice
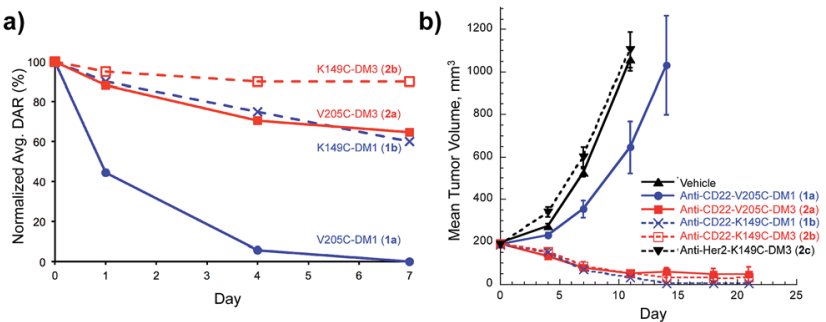

Fig. 2 In vivo stability and efficacy of site-specific antibody-maytansine disulfide conjugates. (a) In vivo stability of antibody maytansine disulfide conjugates in mice. SCID mice were dosed intravenously with $3 \mathrm{mg} \mathrm{kg}^{-1}$ of anti-CD22-DM1 and DM3 (V205C and K149C). At the indicated time points, blood was drawn for determination of the average DAR normalized to day 0 using an affinity-capture LC-MS method. ${ }^{27}$ (b) In vivo efficacy of antibody maytansine disulfide conjugates in mice bearing BJAB.luc human non-Hodgkin lymphoma xenografts. SCID mice were subcutaneously implanted with 20 million tumor cells and administered a single IV dose (day 0) of vehicle or conjugates at $3 \mathrm{mg} \mathrm{kg}^{-1}\left(\sim 90 \mu \mathrm{g} \mathrm{m}^{-2}\right)$ when average tumor size reached $\sim 190 \mathrm{~mm}^{3}$. Mean tumor volumes $( \pm$ SEM) are plotted over time (days post dose). 


$$
\begin{aligned}
& \text { Site-specific (Cys) } \\
& \begin{array}{l}
\text { Cys-DM1 (4): } \mathrm{R}=\mathrm{H}, \mathrm{n}=1 \\
\mathrm{Cys}-\mathrm{DM} \text { (5): } \mathrm{R}=\mathrm{Me}, \mathrm{n}=2
\end{array}
\end{aligned}
$$

Fig. 3 Maytansine disulfide conjugate lysosomal catabolites: Cys catabolites expected from site-specific disulfide conjugates and Lys catabolites resulting from heterogeneous conjugates prepared with heterobifunctional linkers.

(Fig. 2b). Conjugates were administered at a single dose of $3 \mathrm{mg}$ $\mathrm{kg}^{-1}$ and tumor volume was measured over time. Consistent with the in vivo stability data, the least stable conjugate, V205CDM1 (1a), was also the least efficacious, resulting in modest tumor growth delay. Increasing stability either through site (K149C-DM1, 1b) or addition of a methyl group (V205C-DM3, 2a) resulted in complete tumor regression. Furthermore, this activity was target mediated as anti-Her2-K149C-DM3 (2c), the non-target control conjugate, showed no detectable activity and was equivalent to the vehicle control.

Having demonstrated that relatively high stability of the disulfide in circulation can be achieved by appropriate choice of conjugation site, we evaluated the effectiveness of drug release in a target cell. It is well established that both Lys- and Cyslinked antibody-drug conjugates are completely catabolized in the lysosome to an amino acid-linker-drug species, wherein the amino acid portion is a remnant of the antibody attachment site. ${ }^{19,20,28}$ For Lys linked antibody conjugates the catabolites observed are Lys-SPDB-DM1 (6), -DM3 (7), and -DM4 (8) (Fig. 3). ${ }^{19,20}$ For our site-specific Cys disulfide conjugates, the expected catabolites are Cys-DM1 (4) and Cys-DM3 (5). Based on previous data showing that endosomes/lysosomes are oxidizing, ${ }^{9}$ we posit that disulfide metabolites escape the lysosome and are reduced in the cytosol. Thus to compare release of maytansinoid payloads in a target cell we measured stability of the Lys- and Cys-linked catabolites in the presence of a 3.3 fold stoichiometric excess of reductants DTT or GSH (Table 1).

The number of methyl groups on the carbon atom adjacent to the disulfide was the primary determinant for the stability of the disulfide bond, with an increasing number resulting in a sterically encumbered disulfide more resistant to reduction. ${ }^{29}$ Interestingly, within disulfides containing the same substitution, the Cys-catabolites were more readily reduced than Lys- catabolites. This trend is likely a result of the reduced $\mathrm{p} K_{\mathrm{a}}$ for the thiol in Cys, making it a better leaving group than the alkyl thiols present in the Lys-modified metabolites. These results, as well as those at higher glutathione concentrations (Table S1 $\dagger$ ), suggest that drug release inside a target cell is more facile for Cys-linked conjugates than for Lys-linked conjugates.

With an understanding of the impact of disulfide stability on efficacy and disulfide substitution on chemical reduction, we set out to evaluate the influence of disulfide release on efficacy (Fig. 4). We selected the human lymphoma tumor xenograft $\mathrm{BJAB}$, as this model discriminates between conjugates containing cleavable and non-cleavable linkers. ${ }^{30}$ Anti-CD22 conjugates were administered at a single maytansine dose of $50 \mu \mathrm{g} \mathrm{m}^{-2}$ to allow comparison between Lys- and Cys-linked conjugates with differential drug loads. Confirming the importance of release, the non-cleavable maleimide control MPEO-DM1 (1d) was completely stable at this new site (Fig. S2†) yet showed minimal activity. Significantly, while the disulfide conjugate K149C-DM1 (1b, Cys-linked) has similar circulation stability to SPDB-DM4 (9a, Lys-linked), it possessed superior efficacy, indicating that the ability to decouple stability from release results in improved activity in vivo. To confirm that this was not a result of antibody site (Cys vs. Lys) or drug loading, we made MBT-DM4 (9b), a Cys-linked conjugate with the same hindered disulfide as SPDB-DM4 (9a), and demonstrated that the two conjugates were equally efficacious.

Lastly, we sought to develop Cys-linked disulfide chemistry that would enable traceless release of non-thiol drugs (e.g., amines), while retaining high stability in circulation and rapid release of payload (Fig. 5). Traceless, self-immolative disulfide linkers have been used to release phosphates, ${ }^{31}$ alcohols, ${ }^{32-34}$ hydrazides, ${ }^{35}$ and amines ${ }^{36,37}$ for a variety of imaging and therapeutic applications. ${ }^{11}$ Immolation for some of these has been proposed to occur through either cyclization to a 3-membered ring (thiirane or episulfide) or cyclization to a 5 -membered cyclic thiocarbonate. ${ }^{38-40}$ We sought to evaluate the immolative disulfide linker for release of amines, a chemical functional group exemplified by many small molecule drugs and probes. We found that treatment of an immolative disulfide linker-drug $(100 \mu \mathrm{M})$ with a physiologically relevant concentration of a reductant (Cys, $2 \mathrm{mM}$ ) resulted in the production of free drug and thiirane (Fig. S3†) as demonstrated by LC-MS.

Since immolating disulfides have not previously been con-

\begin{tabular}{|c|c|c|c|c|}
\hline Metabolite & Site-specific & \# Me grps ${ }^{a}$ & $\%$ remaining $^{b}(\mathrm{DTT}, 15 \mathrm{~m})$ & $\%$ remaining $^{c}(\mathrm{GSH}, 24 \mathrm{~h})$ \\
\hline Cys-DM1 (4) & Yes & 0 & 67 & 16 \\
\hline Lys-SPDB-DM1 (6) & No & 0 & 87 & 62 \\
\hline Cys-DM3 (5) & Yes & 1 & 97 & 73 \\
\hline Lys-SPDB-DM3 (7) & No & 1 & 98 & 98 \\
\hline Lys-SPDB-DM4 (8) & No & 2 & 100 & 99 \\
\hline
\end{tabular}
nected to an antibody we wanted to establish whether stability was maintained in circulation. One point of concern is the fact

Table 1 Reduction of Cys and Lys disulfide catabolites using dithiothreitol (DTT) and glutathione (GSH)

${ }^{a}$ Number of methyl groups on adjacent atom to disulfide. ${ }^{b} 15 \mu \mathrm{M}$ metabolite, $50 \mu \mathrm{M}$ DTT. ${ }^{c} 15 \mu \mathrm{M}$ metabolite, $50 \mu \mathrm{M}$ GSH. 
a)

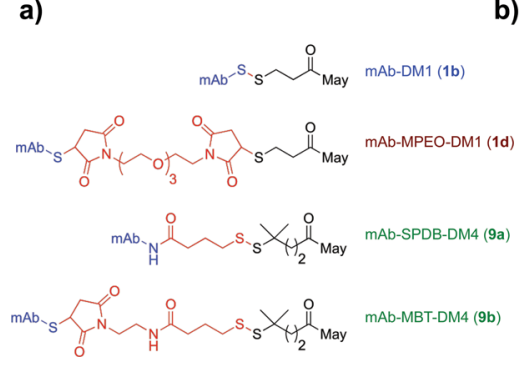

b)

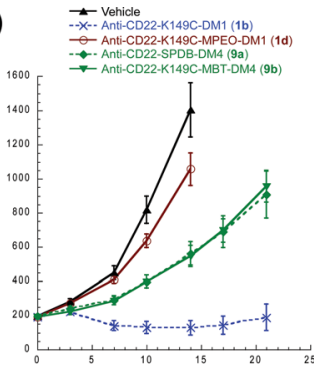

Fig. 4 Impact of release on efficacy for antibody-maytansine conjugates. (a) Structures of antibody-maytansine conjugates. (b) In vivo efficacy of antibody maytansine disulfide conjugates in mice bearing BJAB.luc human non-Hodgkin lymphoma xenografts. SCID mice were subcutaneously implanted with 20 million tumor cells and administered a single IV dose (day 0) of vehicle or conjugates at $50 \mu \mathrm{g} \mathrm{m}^{-2}$ (drug dose) when average tumor size reached $\sim 190 \mathrm{~mm}^{3}$. Mean tumor volumes ( \pm SEM) are plotted over time (days post dose).
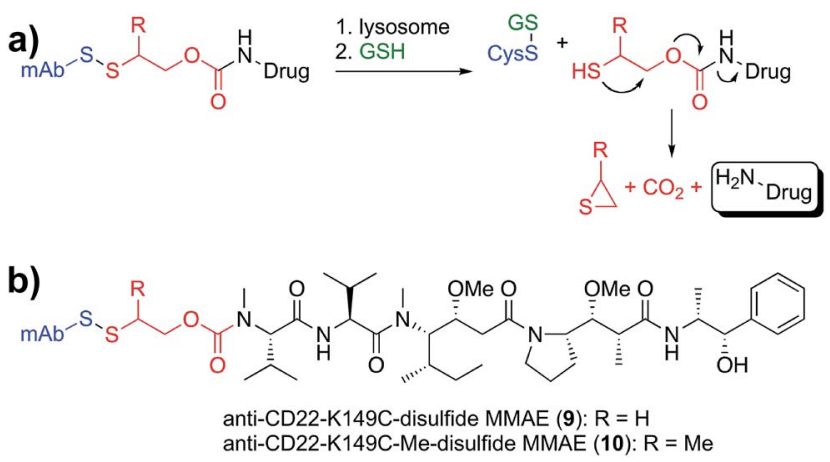

Fig. 5 Application of site-specific disulfide conjugates to aminecontaining drugs. (a) The disulfide conjugate is degraded by proteolysis in the lysosome and reduced by glutathione to generate a free thiol that cyclizes to generate thiirane, carbon dioxide, and the aminecontaining drug. (b) Disulfide MMAE antibody conjugates were generated with (10) and without (9) a neighboring methyl group.

that the electron withdrawing nature of the carbamate group lowers the $\mathrm{p} K_{\mathrm{a}}$ of the thiol and therefore makes it a better leaving group relative to the thiol in the maytansine disulfides described above. Nevertheless, we discovered that conjugates of the two immolating disulfides $(\mathbf{9}, \mathbf{1 0}$, Fig. 5b) had an in vivo stability profile similar to that of the similarly substituted maytansines described above (Fig. S4 $\dagger$ ). Furthermore, the stability of disulfides at site $\mathrm{K} 149 \mathrm{C}$ is not antibody specific as ADCs with anti-Her2 have the same stability as those with antiCD22 (Fig. S5†).

\section{Conclusions}

In summary, we have demonstrated for the first time, the decoupling of stability and release in a disulfide antibody conjugate. This decoupling was accomplished by establishing conjugation chemistry in conjunction with antibody engineering that allowed antibody-mediated stabilization of the disulfide while in circulation and rapid deconjugation upon

complete antibody catabolism inside a target cell. Our sitespecific conjugates are as or more stable than disulfide conjugates employing heterobifunctional crosslinkers but generate catabolites that more readily release the payload. Lastly, we extended our work to immolating disulfide linkers that combine the advantages of antibody protection, rapid cleavage inside a target cell and release of amine-containing drugs. In addition to providing stabilization to disulfides, we believe that the approach of utilizing an antibody to protect a labile chemical functional group will allow improvement in the targeting, half-life, and metabolic stability of small molecule drugs and probes for therapeutic, diagnostic and imaging applications.

\section{Acknowledgements}

We thank Josefa Chuh for her efforts in the initial screen leading to the identification of site LC-K149C and Jinhua Chen, Neelie Zacharias, Yanzhou Liu, Baiwei Lin, and Kewei Xu for helping in the preparation and analysis of the materials described in the study.

\section{Notes and references}

1 E. S. Vitetta, R. J. Fulton, R. D. May, M. Till and J. W. Uhr, Science, 1987, 238, 1098.

2 R. V. J. Chari, M. L. Miller and W. C. Widdison, Angew. Chem., Int. Ed., 2014, 53, 3796.

3 R. S. Greenfield, T. Kaneko, A. Daues, M. A. Edson, K. A. Fitzgerald, L. J. Olech, J. A. Grattan, G. L. Spitalny and G. R. Braslawsky, Cancer Res., 1990, 50, 6600.

4 R. V. Chari, B. A. Martell, J. L. Gross, S. B. Cook, S. A. Shah, W. A. Blättler, S. J. McKenzie and V. S. Goldmacher, Cancer Res., 1992, 52, 127.

5 L. M. Hinman, P. R. Hamann, R. Wallace, A. T. Menendez, F. E. Durr and J. Upeslacis, Cancer Res., 1993, 53, 3336.

6 R. V. Chari, K. A. Jackel, L. A. Bourret, S. M. Derr, B. M. Tadayoni, K. M. Mattocks, S. A. Shah, C. Liu, W. A. Blättler and V. S. Goldmacher, Cancer Res., 1995, 55, 4079.

7 I. Ojima, X. Geng, X. Wu, C. Qu, C. P. Borella, H. Xie, S. D. Wilhelm, B. A. Leece, L. M. Bartle, V. S. Goldmacher and R. V. J. Chari, J. Med. Chem., 2002, 45, 5620.

8 R. Y. Zhao, H. K. Erickson, B. A. Leece, E. E. Reid, V. S. Goldmacher, J. M. Lambert and R. V. J. Chari, J. Med. Chem., 2012, 55, 766.

9 C. D. Austin, X. Wen, L. Gazzard, C. Nelson, R. H. Scheller and S. J. Scales, Proc. Natl. Acad. Sci. U. S. A., 2005, 102, 17987-17992.

10 G. Saito, J. A. Swanson and K.-D. Lee, Adv. Drug Delivery Rev., 2003, 55, 199.

11 M. H. Lee, Z. Yang, C. W. Lim, Y. H. Lee, S. Dongbang, C. Kang and J. S. Kim, Chem. Rev., 2013, 113, 5071.

12 M. T. Kim, Y. Chen, J. Marhoul and F. Jacobson, Bioconjugate Chem., 2014, 25, 1223.

13 J. R. Junutula, H. Raab, S. Clark, S. Bhakta, D. D. Leipold, S. Weir, Y. Chen, M. Simpson, S. P. Tsai, M. S. Dennis, Y. Lu, Y. G. Meng, C. Ng, J. Yang, C. C. Lee, E. Duenas, 
J. Gorrell, V. Katta, A. Kim, K. McDorman, K. Flagella, R. Venook, S. Ross, S. D. Spencer, W. Lee Wong, H. B. Lowman, R. Vandlen, M. X. Sliwkowski, R. H. Scheller, P. Polakis and W. Mallet, Nat. Biotechnol, 2008, 26, 925.

14 J. R. Junutula, K. M. Flagella, R. A. Graham, K. L. Parsons, E. Ha, H. Raab, S. Bhakta, T. Nguyen, D. L. Dugger, G. Li, E. Mai, G. D. Lewis Phillips, H. Hiraragi, R. N. Fuji, J. Tibbitts, R. Vandlen, S. D. Spencer, R. H. Scheller, P. Polakis and M. X. Sliwkowski, Clin. Cancer Res., 2010, 16, 4769.

15 L. Brülisauer, M. A. Gauthier and J.-C. Leroux, J. Controlled Release, 2014, 195, 147.

16 P. R. Hamann, L. M. Hinman, C. F. Beyer, D. Lindh, J. Upeslacis, D. A. Flowers and I. Bernstein, Bioconjugate Chem., 2002, 13, 40.

17 J. Lambert, Drugs Future, 2010, 35, 471.

18 H. Xie and W. A. Blättler, Expert Opin. Biol. Ther., 2006, 6, 281.

19 H. K. Erickson, W. C. Widdison, M. F. Mayo, K. Whiteman, C. Audette, S. D. Wilhelm and R. Singh, Bioconjugate Chem., 2010, 21, 84.

20 H. K. Erickson, P. U. Park, W. C. Widdison, Y. V. Kovtun, L. M. Garrett, K. Hoffman, R. J. Lutz, V. S. Goldmacher and W. A. Blättler, Cancer Res., 2006, 66, 4426.

21 S. P. Trimble, D. Marquardt and D. C. Anderson, Bioconjugate Chem., 1997, 8, 416-423.

22 M. Steiner, I. Hartmann, E. Perrino, G. Casi, S. Brighton, I. Jelesarov, G. J. L. Bernardes and D. Neri, Chem. Sci., 2013, 4, 297-302.

23 E. Perrino, M. Steiner, N. Krall, G. J. L. Bernardes, F. Pretto, G. Casi and D. Neri, Cancer Res., 2014, 74, 2569-2578.

24 G. J. L. Bernardes, G. Casi, S. Trüssel, I. Hartmann, K. Schwager, J. Scheuermann and D. Neri, Angew. Chem., Int. Ed., 2012, 51, 941.

$25 \mathrm{~W}$. C. Widdison, S. D. Wilhelm, E. E. Cavanagh, K. R. Whiteman, B. A. Leece, Y. Kovtun, V. S. Goldmacher, H. Xie, R. M. Steeves, R. J. Lutz, R. Zhao, L. Wang, W. A. Blättler and R. V. J. Chari, J. Med. Chem., 2006, 49, 4392. 26 B.-Q. Shen, K. Xu, L. Liu, H. Raab, S. Bhakta, M. Kenrick, K. L. Parsons-Reponte, J. Tien, S.-F. Yu, E. Mai, D. Li, J. Tibbitts, J. Baudys, O. M. Saad, S. J. Scales, P. J. McDonald, P. E. Hass, C. Eigenbrot, T. Nguyen, W. A. Solis, R. N. Fuji, K. M. Flagella, D. Patel, S. D. Spencer, L. A. Khawli, A. Ebens, W. L. Wong, R. Vandlen, S. Kaur, M. X. Sliwkowski, R. H. Scheller, P. Polakis and J. R. Junutula, Nat. Biotechnol., 2012, 30, 184.
27 K. Xu, L. Liu, O. M. Saad, J. Baudys, L. Williams, D. Leipold, B. Shen, H. Raab, J. R. Junutula, A. Kim and S. Kaur, Anal. Biochem., 2011, 412, 56.

28 S. O. Doronina, B. A. Mendelsohn, T. D. Bovee, C. G. Cerveny, S. C. Alley, D. L. Meyer, E. Oflazoglu, B. E. Toki, R. J. Sanderson, R. F. Zabinski, A. F. Wahl and P. D. Senter, Bioconjugate Chem., 2006, 17, 114.

29 B. A. Kellogg, L. Garrett, Y. Kovtun, K. C. Lai, B. Leece, M. Miller, G. Payne, R. Steeves, K. R. Whiteman, W. Widdison, H. Xie, R. Singh, R. V. J. Chari, J. M. Lambert and R. J. Lutz, Bioconjugate Chem., 2011, 22, 717.

30 A. G. Polson, J. Calemine-Fenaux, P. Chan, W. Chang, E. Christensen, S. Clark, F. J. de Sauvage, D. Eaton, K. Elkins, J. M. Elliott, G. Frantz, R. N. Fuji, A. Gray, K. Harden, G. S. Ingle, N. M. Kljavin, H. Koeppen, C. Nelson, S. Prabhu, H. Raab, S. Ross, D. S. Slaga, J.-P. Stephan, S. J. Scales, S. D. Spencer, R. Vandlen, B. Wranik, S.-F. Yu, B. Zheng and A. Ebens, Cancer Res., 2009, 69, 2358-2364.

31 G. Gish and F. Eckstein, Science, 1988, 240, 1520.

32 L. R. Jones, E. A. Goun, R. Shinde, J. B. Rothbard, C. H. Contag and P. A. Wender, J. Am. Chem. Soc., 2006, 128, 6526.

33 P. A. Wender, E. A. Goun, L. R. Jones, T. H. Pillow, J. B. Rothbard, R. Shinde and C. H. Contag, Proc. Natl. Acad. Sci. U. S. A., 2007, 104, 10340.

34 E. A. Dubikovskaya, S. H. Thorne, T. H. Pillow, C. H. Contag and P. A. Wender, Proc. Natl. Acad. Sci. U. S. A., 2008, 105, 12128.

35 I. R. Vlahov, H.-K. R. Santhapuram, P. J. Kleindl, S. J. Howard, K. M. Stanford and C. P. Leamon, Bioorg. Med. Chem. Lett., 2006, 16, 5093.

36 A. Satyam, Bioorg. Med. Chem. Lett., 2008, 18, 3196.

37 C. Batisse, E. Dransart, R. Ait Sarkouh, L. Brulle, S.-K. Bai, S. Godefroy, L. Johannes and F. Schmidt, Eur. J. Med. Chem., 2015, 95, 483.

38 L. W. C. Miles and L. N. Owen, J. Chem. Soc., 1952, 817.

39 S. A. Kularatne, C. Venkatesh, H.-K. R. Santhapuram, K. Wang, B. Vaitilingam, W. A. Henne and P. S. Low, J. Med. Chem., 2010, 53, 7767.

40 A. K. Jain, M. G. Gund, D. C. Desai, N. Borhade, S. P. Senthilkumar, M. Dhiman, N. K. Mangu, S. V. Mali, N. P. Dubash, S. Halder and A. Satyam, Bioorg. Chem., 2013, 49, 40 . 